\title{
Significados da agricultura familiar pela perspectiva local: o caso da Associação dos Agricultores Familiares de São Pedro da Serra (Rio de Janeiro, Brasil)
}

\author{
The meanings of family agriculture from the local perspective: the case of the \\ Association of Family Farmers of São Pedro da Serra (Rio de Janeiro, Brazil) \\ Los significados de la agricultura familiar por la óptica local: el caso \\ de la Asociación de los Agricultores Familiares de São Pedro da Serra \\ (Rio de Janeiro, Brasil) \\ Cristiane Passos de Mattos ${ }^{1}$ \\ Marta de Azevedo Irving ${ }^{2}$ \\ Lilia dos Santos Seabra ${ }^{3}$
}

Recebido em 16/08/2019; revisado e aprovado em 18/12/2019; aceito em 11/03/2020

DOI: http://dx.doi.org/10.20435/inter.v22i1.2688

\begin{abstract}
Resumo: O artigo busca interpretar a dinâmica da agricultura familiar nos limites da Área de Proteção Ambiental Macaé de Cima, pela perspectiva dos atores da Associação dos Agricultores Familiares de São Pedro da Serra e Adjacências. A percepção local sobre a agricultura familiar transcende o seu entendimento como atividade produtiva e se traduz por meio da religiosidade, do vínculo com a natureza e da relação com os turistas que visitam a região.
\end{abstract}

Palavras-chave: agricultura familiar; narrativas locais; atores sociais; São Pedro da Serra.

Abstract: The article aims to interpret the dynamics of family agriculture in the limits of the Macaé de Cima Environmental Protection Area, from the perspective of the social actors of the Association of Family Farmers of São Pedro da Serra and Surroundings. The local perception about family agriculture transcends its understanding as a productive activity. This is translated by its religiosity, by its relation with nature, and with the tourists that visit the region.

Keywords: family agriculture; local narratives; social actors; São Pedro da Serra.

Resumen: El artículo busca interpretar la dinámica de la agricultura familiar en los límites del Área de Protección Ambiental Macaé de Cima, por la perspectiva de los actores de la Asociación de Agricultores Familiares de São Pedro da Serra y Adyacencias. La percepción local sobre la agricultura familiar trasciende su comprensión como actividad productiva y se traduce por medio de la religiosidad, del vínculo con la naturaleza y de la relación con los turistas que visitan el área.

Palabras claves: agricultura familiar; narrativas locales; actores sociales; São Pedro da Serra.

\section{INTRODUÇÃO}

Embora a agricultura familiar envolva $84 \%$ dos estabelecimentos rurais brasileiros e responda por 38\% do valor bruto da produção agropecuária do Brasil (IBGE, 2017), a compreensão sobre as dinâmicas sociais e culturais a ela associadas ainda constitui, atualmente, um desafio para se pensar o desenvolvimento local (CHEUNG, 2013).

Considerando esse desafio como central para pensar alternativas de desenvolvimento que se traduzam como oportunidades para a melhoria da qualidade de vida de quem reside no campo, o objetivo deste artigo é interpretar, preliminarmente, a dinâmica da agricultura familiar

\footnotetext{
${ }^{1}$ Centro Federal de Educação Tecnológica Celso Suckow da Fonseca (CEFET-RJ), Nova Friburgo, Rio de Janeiro, Brasil.

${ }^{2}$ Universidade Federal do Rio de Janeiro (UFRJ), Rio de Janeiro, Rio de Janeiro, Brasil.

${ }^{3}$ Universidade do Estado do Rio de Janeiro (UERJ), Rio de Janeiro, Rio de Janeiro, Brasil.
} 
nos limites da Área de Proteção Ambiental Macaé de Cima (APAMC) pela leitura dos agricultores da Associação de Agricultores Familiares de São Pedro da Serra e Adjacências (AFASPS), situada em Nova Friburgo, RJ (Brasil). Essa Associação é a única formalizada na bacia do Rio Macaé e envolve, atualmente, oitenta membros oficialmente registrados, com área aproximada das propriedades em torno de 2.260 hectares (EMATER-RIO, 2018).

Tendo em vista esse contexto, o ponto de partida para a reflexão proposta se origina no reconhecimento de que estudos como esse tendem a representar uma oportunidade ímpar para que se possa transcender a leitura recorrente do ambiente rural como periférico e marginal, sob as perspectivas social, econômica e cultural (CARNEIRO, 2008). Com essa expectativa, a motivação para essa pesquisa decorre, ainda, do interesse em interpretar a realidade agrária com base em uma compreensão mais ampliada da dinâmica rural, que considere as suas múltiplas dimensões (SILVA; GROSSI; CAPANHOLA, 2002).

Com base nessas premissas, a questão de pesquisa que orienta o percurso investigativo é: que significados são atribuídos à agricultura familiar pelos agricultores da AFASPS? Para tentar responder a essa questão, a abordagem metodológica adotada envolveu pesquisa bibliográfica sobre o tema e a região em foco, além de entrevistas narrativas e observação participante na dinâmica de funcionamento da referida Associação.

Com esse direcionamento, a estrutura do artigo envolve, em um primeiro momento, um breve balizamento sobre a agricultura familiar no Brasil. Em seguida, apresenta-se sinteticamente o contexto histórico e geográfico da agricultura familiar na área de inserção da AFASPS, situada nos limites de uma unidade de conservação, a Área de Proteção Ambiental de Macaé de Cima (APAMC). Na sequência, são apresentados os resultados da análise realizada para atender ao objetivo formulado e, também, as considerações finais, a partir da experiência da pesquisa.

\section{METODOLOGIA}

Para apoiar o objetivo formulado, o percurso metodológico para a elaboração deste artigo envolveu (1) pesquisa bibliográfica sobre a agricultura familiar, nos limites da APAMC; (2) observação participante envolvendo a dinâmica da AFASPS, no período de junho a novembro de 2017, com registro em caderno de campo e realização de três entrevistas narrativas dirigidas a agricultores que representam lideranças na diretoria da Associação; (3) sistematização e análise do material pesquisado à luz da técnica de Análise de Conteúdo (BARDIN, 2011).

Na primeira etapa, desenvolvida em maio de 2017, a pesquisa bibliográfica envolveu um processo de busca da produção acadêmica disponível, com base nos termos "agricultura familiar" e "Macaé de Cima", no catálogo de Teses e Dissertações da Capes ${ }^{5}$. Por essa via, foram obtidas dezoito pesquisas concluídas no período entre 1988 e 2014.

A fase de campo, por sua vez, caracterizou a segunda etapa metodológica da pesquisa e foi desenvolvida junto à AFASPS, cuja sede situa-se na localidade de Bocaina dos Blaudts, em São Pedro da Serra, Nova Friburgo, RJ. Nesse contexto, a inserção na dinâmica da referida

\footnotetext{
${ }^{4}$ Vale destacar, ainda, que, no município de Nova Friburgo, o percentual da produção agropecuária em relação ao Produto Interno Público (PIB) do município de Nova Friburgo é em torno de 6\%, com valor estimado em R\$ 4,4 bilhões por ano (EMATER-RIO, 2018).

5 Disponível em: http://www-periodicos-capes-gov-br.ez29.periodicos.capes.gov.br/index.php? option\%3Dcom_ phome\%26ltemid\%3D68\%26. Acesso em: 13 jul. 2018.
} 
Associação ocorreu por meio de uma ação engajada de pesquisa que se traduziu em um elo de comprometimento e imersão ética junto ao cotidiano dos pesquisados. No ambiente dessa Associação, que atualmente conta com 80 sócios, foram acompanhadas, por meio da observação participante, seis assembleias ordinárias, duas reuniões internas da diretoria e um evento cultural produzido, anualmente, pelos agricultores dessa Associação, denominado 5a EXPO AFASPS, conforme sistematizado no Quadro 1, a seguir.

Quadro 1 - Síntese das atividades de observação participante

\begin{tabular}{|c|c|c|}
\hline Ambiente de observação & Datas & Descrição \\
\hline $\begin{array}{l}\text { Assembleias ordinárias da } \\
\text { AFASPS }\end{array}$ & $\begin{array}{l}12 / 06 / 2017 \\
10 / 07 / 2017 \\
14 / 08 / 2017 \\
11 / 09 / 2017 \\
16 / 10 / 2017\end{array}$ & $\begin{array}{l}\text { As assembleias são reuniões mensais, direcionadas à } \\
\text { participação de todos os associados, realizadas sempre } \\
\text { às segundas-feiras, com início às 19h, na sede da } \\
\text { AFASPS. }\end{array}$ \\
\hline $\begin{array}{l}\text { 5a Exposição anual da } \\
\text { AFASPS }\end{array}$ & $17 / 06 / 2017$ & $\begin{array}{l}\text { Festa realizada com base em inúmeros mutirões, } \\
\text { orientada pela necessidade de levantar fundos e de } \\
\text { aumentar a visibilidade da Associação em sua região. }\end{array}$ \\
\hline $\begin{array}{l}\text { Reuniões da Diretoria } \\
\text { AFASPS }\end{array}$ & $\begin{array}{l}02 / 07 / 2017 \\
07 / 08 / 2017\end{array}$ & $\begin{array}{l}\text { Reuniões exclusivas para os membros que constituem } \\
\text { a diretoria da AFASPS realizadas na residência do } \\
\text { presidente da Associação. }\end{array}$ \\
\hline
\end{tabular}

Fonte: Elaboração própria (2018).

Vale ressaltar, ainda, que a observação participante tem origem no interacionismo simbólico (HAGUETTE, 1987) e esteve orientada por diretrizes compiladas por Valladares (2007), por meio de aportes advindos da obra de White (2005). Assim, primeiramente, houve uma fase de negociação junto à diretoria da Associação para a realização da pesquisa, em maio de 2017, e, após esse momento, foi possível a compreensão sobre as relações de poder no âmbito dessa organização, visando a uma melhor interpretação da estrutura social local. Na sequência, ocorreu uma imersão no cotidiano local. Em razão das reuniões não serem públicas, ou seja, não serem abertas às manifestações de indivíduos não associados ${ }^{6}$, essa relação teve de ser construída a partir de uma base de confiança e, assim, laços pessoais foram também estabelecidos com alguns atores locais, que passaram a ter papel de intermediários entre a Associação e a interlocução da pesquisa.

Nesse contexto, as entrevistas narrativas estiveram orientadas por uma questão gerativa " $O$ que é ser agricultor familiar?", e o material obtido foi integralmente gravado e transcrito, tendo sido realizados os procedimentos éticos quanto às salvaguardas para o anonimato e, também, a assinatura de Termos de Consentimento Livre e Esclarecido ${ }^{7}$. As informações sobre essa fase da pesquisa estão sistematizadas no Quadro 2, a seguir.

\footnotetext{
${ }^{6}$ Exceto em casos em que o visitante solicita uma liberação da diretoria da referida Associação referente à fala, com antecedência mínima de uma semana, e tem seu pedido deferido.

${ }^{7}$ Considerando que o artigo integra resultados de pesquisa de doutorado, os instrumentos de pesquisa foram aprovados pelo Comitê de Ética e Pesquisa da Universidade Federal do Rio de Janeiro (UFRJ), em 18 de maio de 2017, sob o número CAAE 66470417.6.0000.5582.
} 
Quadro 2 - Síntese das entrevistas realizadas

\begin{tabular}{|c|c|c|c|l|}
\hline $\begin{array}{c}\text { Código de } \\
\text { identificação do } \\
\text { entrevistado }\end{array}$ & Idade & Sexo & $\begin{array}{c}\text { Data da } \\
\text { entrevista }\end{array}$ & \multicolumn{1}{c|}{ Local da entrevista } \\
\hline A1 & 65 & Masculino & $24 / 06 / 2017$ & $\begin{array}{l}\text { Localidade da Benfica, São Pedro } \\
\text { da Serra, Nova Friburgo, RJ }\end{array}$ \\
\hline A2 & 49 & Masculino & $24 / 06 / 2017$ & $\begin{array}{l}\text { Localidade da Benfica, São Pedro } \\
\text { da Serra, Nova Friburgo, RJ }\end{array}$ \\
\hline A3 & 23 & Masculino & $11 / 07 / 2017$ & $\begin{array}{l}\text { Centro de São Pedro da Serra, } \\
\text { Nova Friburgo, RJ }\end{array}$ \\
\hline
\end{tabular}

Fonte: Elaboração própria (2018).

A terceira etapa investigativa foi conduzida por meio da adaptação da técnica de Análise de Conteúdo ${ }^{8}$ (BARDIN, 2011) e esteve voltada à interpretação dos significados da agricultura familiar, por meio de três temas focais, delimitados a posteriori, ou seja, após a leitura aprofundada das informações obtidas em diário de campo e nas entrevistas: 1) Nuances religiosas associadas às práticas da agricultura familiar local, 2) O vínculo com a natureza e 3) Contexto de interação com o turista. Por essa via, os significados da agricultura familiar puderam ser interpretados, a partir dos olhares e das percepções dos próprios agricultores.

Considerando esse percurso metodológico e buscando avançar na discussão proposta neste artigo, pretende-se, a seguir, sintetizar o contexto da agricultura familiar no Brasil e, especificamente, no contexto fluminense, tendo em vista a necessidade da compreensão das bases da dinâmica socioeconômica rural no país para que se possa contextualizar o caso estudado.

\section{UM BREVE BALIZAMENTO SOBRE A AGRICULTURA FAMILIAR NO BRASIL: PARA CONTEXTUALIZAR O CASO ESTUDADO}

Não seria possível alcançar o objetivo proposto neste artigo, centrado na interpretação das narrativas dos próprios agricultores, sem a compreensão do contexto da própria dinâmica da agricultura familiar no país e, também, no contexto específico do Estado do Rio de Janeiro.

Assim, um primeiro ponto a se considerar nesta reflexão é que agricultores familiares, no caso brasileiro, são reconhecidos, no âmbito das políticas públicas nacionais (BRASIL, 1996), como aqueles indivíduos que desenvolvem atividades agrícolas em pequenas propriedades, menores do que quatro módulos fiscais, e que utilizam, de modo predominante, mão de obra da própria família, cuja renda do estabelecimento rural correspondente à, pelo menos, metade do total da renda da família. Segundo a legislação vigente, um módulo fiscal representa uma unidade de medida, em hectares, cujo valor é fixado pelo Instituto Nacional de Colonização e Reforma Agrária (INCRA), sendo a sua extensão definida de acordo com o município onde está localizada a propriedade, mas variando, no caso brasileiro, entre 5 e 110 hectares (INCRA, 2018). Vale destacar ainda que, no Estado do Rio de Janeiro, o módulo fiscal abrange dez hectares (INCRA, 2018). Além disso, no plano nacional, silvicultores, aquicultores, extrativistas, pescadores, indígenas, quilombolas e assentados da reforma agrária, nessas condições, são também considerados como agricultores familiares pela ótica governamental, no Brasil (BRASIL, 1996).

\footnotetext{
${ }^{8}$ Esta técnica teve origem nas décadas de 1940 e 1950, nos Estados Unidos da América, e é possível afirmar que ela foi concebida com o objetivo de ser aplicável a múltiplas formas de comunicação (BARDIN, 2011).
} 
Em termos de sua importância, a agricultura familiar representa uma estratégia fundamental para o abastecimento de alimentos no plano nacional, sendo, portanto, um setor-chave para o mercado interno, uma vez que responde por $50 \%$ da produção de alimentos que compõem a cesta básica do país (BRASIL, 2017). Além disso, a atividade da agricultura familiar constitui a principal ocupação em postos de trabalho no campo, sendo, também, fundamental à geração da renda para a população rural brasileira (BRASIL, 2017) e, por consequência, para o desempenho do país com relação ao processo de desenvolvimento humano e social (GUANZIROLI, et al. 2001). Vale destacar, ainda, que essa atividade representa a base da economia de $90 \%$ dos municípios brasileiros, com até vinte mil habitantes (EMBRAPA, 2018) ${ }^{9}$, sendo essa primordial em estratégias de desenvolvimento nacional e, particularmente, no plano local.

No âmbito dessa reflexão e considerando o desenvolvimento local como um caminho potencial para a melhoria da qualidade de vida no campo, por meio de ações pensadas e executadas localmente (BUARQUE, 1999), interpretar a agricultura familiar pela perspectiva dos próprios agricultores representa, assim, um caminho essencial para a elaboração de estratégias governamentais com essa finalidade (MEDINA; NOVAES, 2014).

Pelas razões expostas, investigar contextos específicos da agricultura familiar tende a representar uma via para a identificação de caminhos possíveis para o desenvolvimento local, principalmente no contexto do Estado do Rio de Janeiro, uma unidade da Federação sujeita a graves contextos de desigualdade social no meio rural, sendo, inclusive, considerado como um dos estados menos expressivos no cenário nacional de produção agropecuária (CARNEIRO; TEIXEIRA, 2012), tendo em vista que, atualmente, responde somente por $4 \%$ da produção agropecuária nacional (EMATER-RIO, 2018). Além disso, parece claro que os desafios para se pensar a agricultura em território fluminense são inúmeros, considerando, ainda, o fato de que o panorama agrário vem sendo fortemente influenciado por novas formas de sociabilidade e de relações, decorrentes de um expressivo crescimento de atividades não agrícolas no campo, tais como o turismo, que acabam por ressignificar o rural (CARNEIRO, 2008).

Tendo em vista que os hábitos e as experiências dos agricultores fornecem pistas para se interpretar a dinâmica sociocultural envolvida nessa atividade (CHEUNG, 2013) e partindose da premissa de que a investigação dos laços comunitários constitui um tema de relevância nesse debate (BERGAMASCO; DELGADO, 2017), busca-se, a seguir, interpretar os significados na agricultura familiar pela ótica local, em São Pedro da Serra, na região serrana do Estado do Rio de Janeiro, onde a pluriatividade e a expansão do turismo têm marcado a dinâmica social das áreas rurais (MARAFON; RIBEIRO, 2006).

\section{O CONTEXTO GEOGRÁFICO E HISTÓRICO DA ASSOCIAÇÃO DE AGRICULTORES FAMILIARES DE SÃO PEDRO DA SERRA E ADJACÊNCIAS (AFASPS)}

Um primeiro fato a se considerar, nesta análise, é que a institucionalização da AFASPS ocorreu em 2011, em decorrência do interesse dos agricultores em ter acesso aos recursos do Programa Rio Rural (CALDAS, 2014), uma política do governo estadual, iniciada em 2008, com o objetivo de financiar projetos voltados à agricultura familiar, com recursos do Banco Mundial

\footnotetext{
${ }^{9}$ Vale destacar ainda que, em âmbito global, a agricultura familiar brasileira é reconhecida como o oitavo principal setor de produção de alimentos, com um faturamento anual da ordem de 55,2 bilhões de dólares (BRASIL, 2018).
} 
(RANGEL; OLIVEIRA; MOREIRA, 2016) ${ }^{10}$, o que foi alcançado pelos associados, após a criação da Associação.

Cabe destacar, ainda, que a organização se localiza nos limites da Área de Proteção Ambiental Macaé de Cima (APAMC), uma unidade de conservação (UC) de uso sustentáve ${ }^{11}$ (BRASIL, 2000), criada em âmbito estadual, por meio Decreto n. 29.213, de 14 de setembro de 2001, sob a gestão do Instituto Estadual do Ambiente (INEA-RJ), desde então. Localizada, majoritariamente, em Nova Friburgo, município da região serrana do Estado do Rio de Janeiro ${ }^{12}$, essa UC abriga expressiva cobertura florestal, envolvendo inúmeras espécies da fauna e flora em risco de extinção e/ou endêmicas (RIO DE JANEIRO, 2001). Sendo assim, a motivação para o estabelecimento da AFASPS decorreu, também, do desejo de alguns agricultores, à época, de assegurarem a sua representação junto às esferas da gestão da referida área protegida, mais notadamente, ao próprio Conselho Consultivo da APAMC, uma instância deliberativa de participação social (CALDAS, 2014). Importante enfatizar também que a referida Associação constitui, atualmente, o único coletivo organizado de agricultura familiar, no território de abrangência dessa unidade de conservação.

Mas não se pode negligenciar, nesta breve análise, que, na região, desde a década de 1950, já havia uma cultura de associativismo dos agricultores mediada pela influência das comunidades eclesiais de base (entre as quais, merece destaque a comunidade paroquial católica denominada Ação Rural de São Sebastião de Lumiar ${ }^{13}$, criada em 1953, segundo Schiavo [1997]), associadas à Igreja Católica e, também, aos movimentos de alfabetização e escolarização da população rural. Apesar desses antecedentes, vale destacar que a AFASPS não tem vínculo direto com nenhuma organização de cunho religioso desde a sua fundação. Além disso, abriga, em sua composição, a representação do sindicato rural do município de Nova Friburgo, podendo, inclusive, emitir declarações voltadas aos direitos trabalhistas e previdenciários para os associados.

Um ponto importante a ser enfatizado é que, desde a época de seu estabelecimento, a referida organização passou a contar com uma adesão expressiva de agricultores, que, atualmente, somam oitenta associados e, em linhas gerais, desenvolvem práticas convencionais de produção agrícola, pautadas pelo uso de insumos e agrotóxicos, em uma lavoura mercantil de pequena escala, com destaque para as raízes, como a batata-inglesa, o inhame, a batata-baroa, além de couve-flor, batata-doce, banana, entre outros itens agrícolas. Estes escoam a sua produção principalmente para entrepostos agrícolas regionais, situados no município de Nova Friburgo, RJ.

Não se pode negligenciar, também, que a maioria dos sócios cultiva alimentos para o próprio

\footnotetext{
${ }^{10}$ Este programa esteve orientado pelo compromisso de apoiar práticas sustentáveis em território fluminense, para que os agricultores pudessem desenvolver ações para a preservação de nascentes, a proteção de matas ciliares, a conservação da biodiversidade, entre outras ações (RIO DE JANEIRO, 2014). Implementado pelo governo do Estado do Rio de Janeiro, por meio da Secretaria de Estado de Agricultura e Pecuária (SEAPEC) e da Superintendência de Desenvolvimento Sustentável (SDS), este Programa vem sendo desenvolvido desde 2007, em parceria com Empresa de Assistência Técnica e Extensão Rural do Estado do Rio de Janeiro (EMATER-Rio).

${ }^{11}$ Segundo o Sistema Nacional de Unidades de Conservação (BRASIL, 2000), as unidades de conservação de uso sustentável têm um território estratégico em relação à conservação da biodiversidade, sendo admitido o uso direto de recursos naturais a partir de um zoneamento estabelecido pelo Plano de Manejo da unidade. Neste tipo de território, não há desapropriação de áreas, sendo admitida a propriedade privada.

${ }^{12}$ Com extensão de $350,37 \mathrm{~km}^{2}$, uma pequena porção desta área protegida (cerca de 1.045 hectares) se situa em Casimiro de Abreu, município da região das baixadas litorâneas do mesmo estado (INEA, 2014). Vale destacar que, desde a criação, sua delimitação territorial permanece inalterada.

${ }^{13}$ Esta associação permanece até os dias de hoje vinculada à Paróquia Católica de São Sebastião de Lumiar, sendo ativa nos limites da APAMC.
} 
consumo, como feijão, aipim e milho, além de verduras e ervas medicinais. E, nessa dinâmica, a construção civil figura como uma segunda ocupação de parcela significativa dos associados, sendo também uma característica comum, na região, a pluriatividade, com a atuação de membros da família em atividades não agrícolas, como as de apoio em pousadas ou restaurantes, ou ainda na indústria de confeç̧ões, que vem se expandindo na região.

No plano histórico, a origem da agricultura familiar teve início a partir de 1823, quando a região passou a ser colonizada por imigrantes suíços ${ }^{14}$ (MAYER, 2011), por meio do estabelecimento de pequenas propriedades rurais com mão de obra exclusivamente familiar (PERES et al., 2004). Vale ainda ressaltar que esse movimento surgiu com o recrutamento de imigrantes alemães, naquela época, para fortalecer a dinâmica da então colônia suíça, e esses passaram a receber terras no vale do rio Macaé (MAYER, 2011) ${ }^{15}$.

Esse modelo, baseado em pequenas propriedades familiares, perdurou por todo o século XIX, pois, ainda que alguns poucos colonos tenham passado a adequar as suas propriedades ao formato de latifúndios para a monocultura cafeeira ${ }^{16}$, a maior parte deles manteve sítios de subsistência voltados à produção de alimentos com base na policultura (MAYER, 2011). Vale enfatizar, nesta leitura, que a prática da queimada já era, desde então, recorrente entre esses primeiros colonos, que, em função de estarem distanciados geograficamente da administração da colônia, teriam perdido traços culturais europeus de origem, passando a produzir milho, aipim, e recorrendo aos recursos florestais para assegurar a saúde de suas famílias e para a construção de suas moradias (MAYER, 2011).

Segundo Mayer (2011), esse isolamento teria marcado a região até meados da década de 1950. Mas, de acordo com Peres et al. (2004), foi a partir dos anos 1970, no entanto, com a abertura e melhoria de estradas ligando a região ao centro do município de Nova Friburgo, que as características agrícolas iniciais teriam sido modificadas, com o uso progressivo e intensivo de insumos agrícolas e com a subordinação à economia de mercado, o que passou a envolver uma elevada produção de olerícolas, tomate, pimentão e couve-flor, apenas para citar os principais itens na produção de alimentos. E, por conta desse uso intensivo de insumos agrícolas, inúmeros problemas de saúde e degradação ambiental representam, também, o legado desse período.

É possível afirmar ainda que, a partir desse momento, uma economia local, de base fundamentalmente agrícola, passou a se desenvolver em novas bases, o que teria viabilizado a própria "existência social da comunidade", que envolvia uma dinâmica social de casamentos interfamiliares (MAYER, 2011, p. 20).

Para além da consolidação de uma economia local, vale destacar que essa década, de 1970, constituiu-se também como um período inicial de ascensão do turismo como uma prática social na região (AMADOR, 1997). Mas, no início desse processo, o turismo envolvia um perfil de turistas que viajavam em grupos ou em um contexto familiar, dispostos a enfrentar acessos

\footnotetext{
${ }^{14}$ Os colonos, na origem do processo, foram destinados, pelo então governo imperial, ao vale do Rio Santo Antônio, em 1818, onde atualmente se localiza o centro do município de Nova Friburgo. Estes colonos eram, sobretudo, artesãos e agricultores pobres vindos de um cenário de miséria associado ao inverno rigoroso da Suíça, em 1817 (MAYER, 2011).

${ }^{15}$ Muitas destas terras, foram abandonadas pelos colonos suíços em decorrência da inapropriação destas para o cultivo agrícola (MAYER, 2011).

${ }^{16}$ A criação de São Pedro da Serra, uma das localidades da APAMC, foi realizada, nesta época, mediante autorização expressa de D. Pedro I, "daí resultando provavelmente o nome da localidade de São Pedro" (MAYER, 2011, p. 17).
} 
precários e falta de energia elétrica e que, por essa razão, eram considerados como "pioneiros" ou "aventureiros", segundo a perspectiva de análise de Amador (1997).

A partir da década de 1980, contudo, a redução das áreas destinadas à agricultura, ou, ainda, o decréscimo do número de trabalhadores rurais envolvidos com a produção agrícola, representou um fato expressivo no Brasil (SILVA; GROSSI; CAPANHOLA, 2002), o que também pode ser observado nos limites da APAMC, uma vez que os altos custos iniciais da lavoura (devido à subordinação aos insumos e ao baixo valor dos alimentos produzidos) teriam ocasionado uma mudança de comportamento das gerações mais jovens, que teriam começado a procurar novas atividades para a sua subsistência (PERES et al., 2004). É preciso destacar ainda que o processo de modernização da agricultura e da sociedade brasileira, de um modo geral, contribuiu para gerar "diminuição dos postos de trabalho na agricultura e uma ampliação das atividades nãoagrícolas em territórios rurais", nessa época (CARNEIRO, 2008, p. 14), o que pode ter resultado na dinâmica de pluriatividade que passou a caracterizar a região desde então.

Importante mencionar que a luz elétrica só passou a ser uma realidade na região a partir dessa década, com o aproveitamento das águas para a instalação de usinas, a construção de pequenas hidrelétricas e a consequente cobertura da rede elétrica no centro dos distritos de Lumiar e São Pedro da Serra, RJ. Assim, uma mudança de hábitos se processou, tanto em decorrência da chegada da rede elétrica quanto do asfaltamento da estrada Mury-Lumiar, uma rodovia estadual que passou a permitir a ligação entre a região e a área urbana de Nova Friburgo, em 1982. Em meio a esse processo, as áreas de agricultura passaram a ser paulatinamente abandonadas, tendo sido substituídas, progressivamente, pela ocupação induzida pelo desenvolvimento turístico (REGO, 1988). E na década de 1980, particularmente, observou-se também uma mudança no perfil de turistas que ali chegavam, reconhecidos pelos moradores locais como hippies, ou adeptos do camping selvagem (AMADOR, 1997).

Neste breve exercício retrospectivo, é possível afirmar que, na década subsequente, de 1990, a dinâmica da agricultura na APAMC passou a ser um reflexo direto do que acontecia no país, na mesma época, com o notável declínio da atividade rural em pequena escala, resultante de uma política de barateamento dos alimentos no mercado e da vinculação dos insumos agrícolas ao dólar americano (LOPES, 1996). Sendo assim, entre 1986 e 1996, Lopes (1996, p. 18) afirma que a produtividade por hectare em todo o país foi drasticamente reduzida em termos de áreas de cultivo, o que teria causado "irreparáveis danos ao emprego e à renda rurais". E parece ter sido essa a tendência que caracterizou a dinâmica socioeconômica da região estudada, sendo o alto preço dos insumos o principal fator responsável pela queda da produção agrícola (PERES et al., 2004), o que, por sua vez, passou a influenciar novos usos do território.

Nesse contexto, o turismo passou a estar cada vez mais em evidência, como alternativa produtiva e de renda, na dinâmica local. Isso porque, nessa mesma década (1990), a rede de telefonia alcançou a região, fato que contribuiu, complementarmente, para induzir o aumento do preço da terra e a expansão do turismo (MAYER, 2011). Esta conjuntura, associada ao asfaltamento da estrada entre Lumiar e São Pedro da Serra, em 1995, teria ocasionado um crescimento ainda mais evidente do turismo na região, atraindo, cada vez mais, um público urbano em busca de uma experiência bucólica junto à natureza protegida, o que teria resultado em inúmeros conflitos com os agricultores da região (AMADOR,1997).

Todo esse processo de transformação do espaço rural teria motivado muitos agricultores a abandonarem o lugar em que viviam para se tornarem caseiros em áreas que antes lhes 
pertenciam (MAYER, 2011; REGO, 2010). Vale destacar ainda que, na década de 1990, assistiu-se ao fortalecimento das ações governamentais voltadas à conservação da biodiversidade na região, processo esse que culminou com a criação da APAMC ${ }^{17}$, interpretada, por muitos agricultores e outros atores sociais locais, como uma vitória dos grupos vinculados aos interesses de sitiantes ${ }^{18}$, turistas, ambientalistas e pessoas "de fora" (REGO, 2010).

Além de ser reconhecida como área de elevada biodiversidade, inúmeras outras motivações inspiraram a criação da APAMC em 2001: a sua importância para a manutenção da qualidade da água na região do entorno; a sua relevância para a preservação dos remanescentes de Mata Atlântica e dos campos de altitude; e o seu papel para a proteção das bacias dos mananciais do rio Macaé, rio Bonito, rio das Flores, rio Santo Antônio e demais afluentes ${ }^{19}$ (INEA, 2014).

Neste sentido, não se pode perder de vista que uma Área de Proteção Ambiental (APA) constitui uma categoria de manejo estabelecida para a proteção, em geral, de áreas extensas, nas quais ocorre determinado grau de ocupação humana (BRASIL, 2000). Assim, não seria de se estranhar que a maior parte das localidades, em seu interior, na época e hoje ainda, seja constituída por paisagens rurais com predominância de floresta primária e secundária e remanescentes de Mata Atlântica.

Nos anos iniciais após a criação dessa unidade de conservação, os agricultores e outras lideranças se organizaram em um movimento denominado União das Famílias da Terra (UFT), com o objetivo de contestar a criação da APAMC. Isso porque parte da população rural local se sentiu prejudicada em seus interesses com a efetivação dessa área protegida, principalmente porque a agricultura familiar passou a estar sujeita a inúmeras normas e restrições referentes ao uso do solo, que, na região, resultaram diretamente na repressão à prática da queimada e do pousio ${ }^{20}$, conforme discutido por Carneiro (2010). Assim, o ambiente social, nos primeiros cinco anos após a criação da unidade de conservação, caracterizou-se por um contexto recorrente de embates e conflitos entre os agricultores e demais atores locais e o órgão gestor da APAMC (REGO, 2010), o Instituto do Ambiente do Estado do Rio de Janeiro (INEA-RJ).

Esses conflitos se concretizaram, inclusive, porque os agricultores percebiam a equipe da gestão da APAMC como a origem do processo de coerção às suas práticas tradicionais de manejo da terra (TEIXEIRA, 2009). E, nessa conjuntura, pode-se afirmar que esse teria sido o marco referencial dos conflitos entre agricultores familiares e os grupos e interesses vinculados à gestão da APAMC e/ou aos movimentos ambientalistas, na região, contexto esse que se mantém até os dias atuais.

\footnotetext{
${ }^{17}$ Nesta década, também, houve a criação da Reserva Ecológica de Macaé de Cima, em 1990 (NOVA FRIGURGO, 1990). Uma área de proteção integral, de âmbito municipal, que abrangia, na época, uma extensão correspondente a um quinto da atual área representada pela APAMC. Nesta área, em específico, a porção mais conservada do alto curso do rio Macaé, a atuação de uma associação representativa, Sociedade Macaé de Cima, teve um papel relevante no movimento Pro-APA, voltado à criação da Área de Proteção Ambiental de Macaé de Cima, na esfera estadual (REGO, 2010).

${ }^{18}$ Indivíduos que têm casas de veraneio na região.

${ }^{19}$ O rio Macaé representa o principal eixo hídrico na configuração da APAMC, sendo, portanto, reconhecido como um elemento geográfico focal para as estratégias de conservação da biodiversidade. Este rio se constitui, também, como um recurso hídrico fundamental para o abastecimento de parte significativa das instalações de um expressivo complexo petrolífero situado na área urbana de Macaé, RJ - complexo industrial voltado à exploração de petróleo na bacia de Campos, mantido pela empresa Petróleo Brasileiro S/A (Petrobras), sociedade anônima de capital aberto, cujo maior acionista é o Governo Federal do Brasil (PETROBRAS, s.d.).

${ }^{20}$ O pousio envolve o manejo do solo que incorpora a queimada e o corte da capoeira como práticas agrícolas, tendo sido a fonte de muitos conflitos entre agricultores e órgão ambiental.
} 
Mas, segundo Teixeira (2009), apesar desse cenário de conflitos, parece claro que, nesta época, nos anos 2000, algumas melhorias relacionadas à infraestrutura - acessos terrestres às localidades da região, a ampliação da energia elétrica, a instalação de postos de saúde, escolas e unidades de comércio - passaram a ser percebidas, pelos agricultores familiares como elementos positivos, associados, inclusive, ao avanço do turismo na região. No entanto, pela perspectiva da autora, contraditoriamente, muitos deles passaram a associar a emergência do turismo na região ao aumento da violência, ao incremento do uso de drogas pelos jovens e ao acirramento da disputa pela posse da terra.

Em função dessa dinâmica de expansão do turismo e do avanço de outras atividades não agrícolas na região, tais como as confecções do ramo têxtil de moda íntima, nos anos subsequentes, a desvalorização das práticas agrícolas parece ter sido o resultado do processo na região (ROCHA; DI MAIO; CAMPOS, 2011). E, nesse quadro mais recente, não é de se estranhar que estratos mais jovens da população local não mais se identifiquem com a prática da agricultura familiar (ROCHA, 2012).

Com base no panorama descrito e considerando a importância de se pensar as múltiplas dimensões que envolvem essa prática no campo das Ciências Humanas e Sociais, tendo em vista, também, os seus possíveis rebatimentos no âmbito de eventuais estratégias para o desenvolvimento local, busca-se, a seguir, interpretar os significados da agricultura familiar pela perspectiva dos próprios atores locais, os agricultores, que integram a AFASPS e, por consequência, residem na APAMC.

\section{INTERPRETANDO AS NARRATIVAS: SIGNIFICADOS DA AGRICULTURA FAMILIAR PELA ÓTICA DOS PRÓPRIOS AGRICULTORES}

Conforme anteriormente descrito, foram delimitados três temas focais de análise, estabelecidos a posteriori da leitura, em profundidade do material obtido, com o objetivo de se buscar interpretar, ainda que preliminarmente, os significados da agricultura familiar pela ótica dos próprios agricultores por meio da adaptação da técnica da Análise de Conteúdo (BARDIN, 2011), a saber: 1) Nuances religiosas associadas às práticas da agricultura familiar local, 2) Vínculo com a natureza e 3) Contexto de interação com o turista. A síntese da análise realizada está no Quadro 3, a seguir.

Quadro 3 - Matriz Síntese da análise das narrativas dos agricultores sobre a agricultura familiar

\begin{tabular}{|c|c|c|}
\hline Tema de análise & Descrição & Depoimentos ilustrativos \\
\hline $\begin{array}{l}\text { 1) Nuances } \\
\text { religiosas } \\
\text { associadas às } \\
\text { práticas da } \\
\text { agricultura } \\
\text { familiar local }\end{array}$ & $\begin{array}{l}\text { A noção de } \\
\text { agricultura } \\
\text { familiar } \\
\text { traduzida em } \\
\text { uma leitura de } \\
\text { base cristã }\end{array}$ & $\begin{array}{l}\text { "É, para você ter uma ideia, outro dia tinha uma pessoa } \\
\text { que ia... eu falei que eu ia colher o açaí ali, né, aí ela... eu ia } \\
\text { cortar o palmito, ia cortar mesmo, 'Ah, não, que não sei o } \\
\text { quê, que o senhor não pode fazer isso!'.. eu falei 'Como não } \\
\text { posso? Se eu plantei eu posso colher, eu já plantei, já semeei } \\
\text { lá para os altos, agora eu vou e corto aquela ali, ué, é assim } \\
\text { que funciona', não é? É bíblico... 'Crescei e multiplicai-vos', } \\
\text { 'Dominai todos os peixes, todas as árvores'”. (A2). }\end{array}$ \\
\hline
\end{tabular}




\begin{tabular}{|c|c|c|}
\hline Tema de análise & Descrição & Depoimentos ilustrativos \\
\hline $\begin{array}{l}\text { 2) O vínculo com a } \\
\text { natureza }\end{array}$ & $\begin{array}{l}\text { A natureza } \\
\text { é entendida } \\
\text { como parte } \\
\text { da vida e do } \\
\text { cotidiano do } \\
\text { agricultor }\end{array}$ & $\begin{array}{l}\text { "E só ficou na lavoura quem amava de verdade... aquele cara } \\
\text { que não amava a planta, que não conversa com a planta, que } \\
\text { não conversa com a natureza, ele simplesmente ele saiu..." (A1). } \\
\text { "Nós estamos dentro da natureza e a natureza ela está aqui } \\
\text { para todos viverem dela". (A2). } \\
\text { "Se não fosse... se o agricultor da região nossa fosse um } \\
\text { agricultor devastador, num teria se criado a APA de Macaé } \\
\text { de Cima na nossa região, porque ninguém ia começar a } \\
\text { comprar sítio e plantar árvore. Criou-se a APA porque já existia } \\
\text { uma preservação de mata muito grande como existe e uma } \\
\text { preservação de nascente de rio e tudo mais que eu concordo que } \\
\text { deve ser preservada e deve continuar essa preservação". (A3). } \\
\text { "A área de preservação que sempre existiu, meu avô } \\
\text { preservava uma mata, não deixava ninguém derrubar, e a } \\
\text { mata tá lá até hoje, eu nunca vou ter vontade de derrubar ela } \\
\text { porque é uma mata bonita, eu gosto, preservo a nascente, pra } \\
\text { quê que eu vou fazer isso?" (A3). } \\
\text { "Eu cada vez mais eu respeito a natureza tudo, eu acabei } \\
\text { de falar com você, eu já venho nisso, então eu já estou... eu } \\
\text { converso com a natureza, eu estudo a natureza, eu tenho dias } \\
\text { em que eu vejo coisas incriveis que ela oferece para a gente, } \\
\text { então cada vez eu respeito ela mais, entendeu? Cada vez eu } \\
\text { respeito ela mais". (A1). }\end{array}$ \\
\hline $\begin{array}{l}\text { 3) Contexto de } \\
\text { interação com o } \\
\text { turista }\end{array}$ & $\begin{array}{l}\text { A agricultura } \\
\text { familiar } \\
\text { interpretada } \\
\text { como } \\
\text { elemento de } \\
\text { resistência } \\
\text { cultural, em } \\
\text { um contexto } \\
\text { de interação } \\
\text { com o turista }\end{array}$ & $\begin{array}{l}\text { "Desde criancinha os pais da gente já sempre ensinaram a } \\
\text { gente, a gente já planta o inhame, o milho, o broto de um } \\
\text { camboatá ou de um jacateirão, aí a gente já vai mantendo } \\
\text { ele crescendo... aí já vai vindo a capoeira, a gente mesmo vai } \\
\text { fazendo a capoeira, e o turista não sabe disso, ele não está aí } \\
\text { no dia a dia para saber disso... (A2)". } \\
\text { "Eu acho que o turismo é uma forma só de aumentar a renda } \\
\text { das pessoas na região... aí o agricultor fica meio receado que } \\
\text { o turista pode denunciar ou o que o turista pode falar ou você } \\
\text { tá queimando alguma coisa que a queimada no Estado do Rio } \\
\text { de Janeiro é proibida, aí você vê um turista, você vê que é uma } \\
\text { pessoa que não é morador, você também fica receado, pô... } \\
\text { será que ele não vai me denunciar? Será que ele acha essa } \\
\text { prática... será cumé que ele entende a prática de queima?" } \\
\text { (A3). } \\
\text { "Eles vão logo pegam o celular e denunciam a gente que está } \\
\text { roçando, mas a gente não sabem que a gente está precisando } \\
\text { na verdade..." (A1). } \\
\text { "Deixem a gente plantar, é só o que a gente sabe fazer; se a } \\
\text { gente for retirado, daí a gente vai morrer de fome, é igual tirar } \\
\text { o peixe fora da lagoa" (A1). } \\
\text { "Convivi com o turismo desde quando eu era criança, eu } \\
\text { estudava aí durante a semana, eu estudava na escola, aí } \\
\text { depois da escola eu ajudava o meu pai na roça, aí final de } \\
\text { semana do lado da minha casa tem casa de turista, aí eu tinha } \\
\text { amigos, né, que eram do Rio de Janeiro e que vinham para cá } \\
\text { quase todo final de semana, aí eu já tinha contato com esses } \\
\text { turistas desde criança". (A3). }\end{array}$ \\
\hline
\end{tabular}

Fonte: Elaboração própria (2018). 
Por meio dessa síntese, é possível afirmar que o conteúdo expresso pelos agricultores envolve nuances relacionadas à dinâmica sociocultural local, como a religiosidade cristã, o elo afetivo com a natureza e a relação com o turismo. No quadro anterior, estão apresentados alguns dos trechos obtidos de depoimentos ilustrativos para cada um desses temas. Nesses fragmentos, em linhas gerais, percebe-se a referência a textos sagrados pela ótica cristã, o reconhecimento da relação estreita dos agricultores com a natureza protegida da região, e a percepção do agricultor como detentor do conhecimento da dinâmica local em contraste com o turista que visita a região.

Por meio desse exercício de interpretação, os significados sobre a agricultura familiar parecem estar associados a inúmeras dimensões do cotidiano dos próprios agricultores, como acontece com a religiosidade. Por exemplo, é comum nas falas dos agricultores familiares a menção a versículos da Bíblia. Além disso, a oração do Pai-Nosso constitui um momento prioritário para a abertura e o fechamento de todas as reuniões da Associação. A religiosidade é também expressa em banners, placas e slogans de camisetas produzidas, atualmente, pela referida Associação, tais como "Agricultor: instrumento que Deus deu para manter a vida" e "Família: instituição divina", sobretudo quando relacionada a uma leitura cristã, inspirada no catolicismo ou no pentecostalismo, o que pode ter tido origem no histórico associativo dos agricultores, relacionado às antigas comunidades eclesiais de base, iniciado na década de 1950, conforme anteriormente contextualizado. Essa tendência está articulada com o sentido de religiosidade que se expressa, também, pelo significado da família para a coesão dos laços sociais locais.

Nesse movimento, um segundo fato a se considerar, na análise, é que a leitura local sobre a agricultura familiar parece transcender a sua percepção apenas como prática produtiva, traduzindo, inclusive, o próprio vínculo com a natureza da região. Foi possível perceber que a agricultura familiar é entendida como uma prática cuja vitalidade depende do laço afetivo entre o agricultor e a própria natureza. Assim, os agricultores se reconhecem, de certa maneira, como guardiões da natureza, e não apenas como usuários de recursos naturais da região.

Não se pode perder de vista, também, que essa atividade representa, pela ótica dos agricultores da AFASPS, um caminho de resistência cultural aos processos de mudanças e transformações regionais, principalmente associados à expansão do turismo, o terceiro tema focal de análise .Considerando-se o turismo como um fenômeno social relevante e complexo na dinâmica social local, sobretudo a partir da década de 1970, conforme anteriormente mencionado, pelas narrativas dos agricultores, é possível notar que, algumas vezes, o significado de agricultura familiar parece estar sendo construído como um contraponto à presença do próprio turista, aquele que vem "de fora". Mas é importante também enfatizar que, em linhas gerais, esse turista é contraditoriamente percebido como um ator que contribui positivamente para a geração de renda e, também, negativamente, como um ator exógeno que contribui para o acirramento de conflitos.

Em linhas gerais, a análise realizada sobre a dinâmica local, ainda que preliminar, parece indicar que os significados compartilhados com relação à agricultura familiar se traduzem por meio da religiosidade, do vínculo afetivo com a natureza e das contradições reconhecidas na interação dos moradores locais com os turistas que visitam a região. Esse contexto percebido nos limites da APAMC traduz as múltiplas dimensões interpretativas e subjetividades associadas à prática agrícola. 


\section{CONSIDERAÇÕES FINAIS}

O desenvolvimento de pesquisas sociais que priorizam a perspectiva dos atores locais para interpretar a dinâmica da agricultura familiar, no que tange aos aspectos econômico, socioambiental e simbólico, parece representar um caminho essencial para o aprimoramento da leitura sobre essa prática no contexto brasileiro. Isso porque a interpretação dessa dinâmica tende a ser central para se pensar o desenvolvimento local em áreas rurais em bases sustentáveis e a partir da projeção de cenários, em um horizonte futuro no plano das políticas públicas. E, considerando o contexto fluminense, particularmente, com um potencial agropecuário ainda pouco explorado - representando, atualmente, apenas $4 \%$ da produção agropecuária nacional, de acordo com a EMATER-RIO (2018) - e com ilimitadas possibilidades para as estratégias de desenvolvimento regional, torna-se ainda mais essencial a inovação em políticas públicas, por meio do reconhecimento das práticas e dinâmicas locais nem sempre sintonizadas com os modelos convencionais de manejo agrícola.

Nesse contexto, o presente artigo buscou interpretar, preliminarmente, a dinâmica da agricultura familiar pela ótica dos agricultores que integram a Associação de Agricultores Familiares de São Pedro da Serra e Adjacências (AFASPS). Sendo assim, os significados compartilhados com relação à agricultura familiar foram investigados por meio de um percurso metodológico que envolveu pesquisa bibliográfica, observação participante na dinâmica da Associação e entrevistas narrativas dirigidas a três lideranças de referência local. Com base nesse arcabouço, foi possível apreender os significados da agricultura familiar com relação a três principais temas: a religiosidade, a relação com a natureza e a interação com os turistas. Entre esses temas, é importante mencionar que o turismo atualmente mobiliza grande parte desses atores, pela oportunidade que representa para o seu reconhecimento no plano regional.

Em relação ao caso investigado, interpretar a agricultura familiar pela lente das Ciências Humanas e Sociais, priorizando a ótica local, representou um exercício importante para desmistificar a noção do agricultor familiar como um ator secundário em políticas públicas. Isso porque o agricultor familiar está no centro da dinâmica socioambiental local e, principalmente, constitui um dos protagonistas nos conflitos relacionados à gestão da APAMC.

Além disso, tendo em vista que a agricultura familiar representa um segmento-chave para a economia regional, pelas razões anteriormente expostas, e que as recomendações mais recentes das políticas públicas para o setor indicam a importância de se aprimorar as pesquisas sociais com foco nas localidades onde essa se desenvolve, o esforço empreendido neste ensaio buscou gerar alguns subsídios para o desenvolvimento local no contexto da APAMC, no futuro.

\section{REFERÊNCIAS}

AMADOR, André Bittencourt. O turismo e as transformações sócio-espaciais em Lumiar e São Pedro da Serra, Nova Friburgo-RJ. 1997. Monografia (Graduação em Geografia) - Universidade Federal do Rio de Janeiro, Rio de Janeiro, RJ, 1997.

BARDIN, Laurence. Análise de conteúdo. Lisboa: Edições 70, 2011.

BERGAMASCO, Sonia Maria Pessoa Pereira; DELGADO, Guilherme Costa. Apresentação. In: BERGAMASCO, Sonia Maria Pessoa Pereira; DELGADO, Guilherme Costa (Org.). Agricultura familiar brasileira: desafios e perspectivas de futuro. Brasília: Secretaria Especial de Agricultura e do Desenvolvimento Agrário, 2017. Disponível em http://www.mda.gov.br/sitemda/sites/sitemda/files/user_img_1756/ Agricultura\%20 Familiar_WEB_LEVE.pdf. Acesso em: 11 mar. 2018. 
BRASIL. Secretaria Especial de Agricultura Familiar e do Desenvolvimento Agrário. Agricultura familiar do Brasil é 8 a maior produtora de alimentos do mundo. Brasília-DF, 2018. Disponível em: http://www.mda. gov.br/sitemda/noticias/agricultura-familiar-do-brasil-\%C3\%A9-8\%C2\%AA-maior-produtora-de-alimentosdo-mundo. Acesso em: 28 set. 2018.

BRASIL. Secretaria Especial de Agricultura Familiar e do Desenvolvimento Agrário. Plano Safra da Agricultura Familiar - fortalecer o campo para desenvolver o Brasil 2017/2020. SEAD, Brasília-DF, 2017. Disponível em: http://www.mda.gov.br/sitemda/plano-safra-da-agricultura-familiar-20172020. Acesso em: 13 jul. 2018.

BRASIL. Lei Federal n. 9.985, de 18 de julho de 2000. Regulamenta o art. 225, § 10, incisos I, II, III e VII da Constituição Federal, institui o Sistema Nacional de Unidades de Conservação da Natureza e dá outras providências o. Brasília-DF, 2000. Disponível em: http://www.planalto.gov.br/ccivil_03/leis/L9985.htm. Acesso em: 15 jul. 2016.

BRASIL. Decreto n. 1.946, de 28 de junho de 1996. Cria o Programa Nacional de Fortalecimento da Agricultura Familiar- PRONAF, e dá outras providências. Disponível em: http://www2.camara.leg.br/legin/fed/ decret/1996/decreto-1946-28-junho-1996-435815-publicacaooriginal-1-pe.html. Acesso em: 28 set. 2018.

BUARQUE, S. C. Metodologia de planejamento do desenvolvimento sustentável. Brasília: ॥CA, 1999.

CALDAS, Lia Carla Carneiro. Roteiro de Agroturismo de São Pedro da Serra e Arredores, Nova Friburgo, RJ: potencialidades e limitações. 2014. Dissertação (Mestrado em Práticas em Desenvolvimento Sustentável) - Universidade Federal Rural do Rio de Janeiro, Rio de Janeiro, RJ, 2014.

CARNEIRO, Maria José. "Rural" como categoria de pensamento. Ruris, Campinas, v. 2. n. 1. p. 9-38, 2008. Disponível em: https://www.ifch.unicamp.br/ceres/2008-maria_carneiro.pdf. Acesso em: 11 mar. 2018.

CARNEIRO, Maria José; BERTOLINO, Valéria Freire Allemão; BERTOLINO, Luiz Carlos. Agricultores e território: práticas e saberes. Rio de Janeiro: Trasso Comunicação / CNPq / Faperj, 2010.

CARNEIRO, Maria José; TEIXEIRA, Vanessa Lopes. Para além das dualidades: o rural não agrícola no estado do Rio de Janeiro. In: CARNEIRO, Maria José. (Org.) Ruralidades contemporâneas: modos de viver e pensar o rural na sociedade brasileira. Rio de Janeiro: Mauad X / FAPERJ, 2012.

CHEUNG, Thelma Lucchese. Desenvolvimento da agricultura familiar: investigação sobre o espaço rural e o território como referência para estudar o caso do município de Terenos, MS. Interaçõe,. Campo Grande, v. 14, n. 2, p. 189-95, 2013. Disponível em http://www.interacoes.ucdb.br/article/view/202. Acesso em: 13 jul. 2018.

EMATER-RIO. Empresa de Assistência Técnica e Extensão Rural. Dados da produção agropecuária. Rio de Janeiro: EMATER-RIO, 2018.

EMPRESA BRASILEIRA DE PESQUISA AGROPECUÁRIA (EMBRAPA). Entenda o Código Florestal, adequação ambiental da paisagem rural, Módulos Fiscais. EMBRAPA, Brasília-DF, 2018. Disponível em https://www. embrapa.br/codigo-florestal/area-de-reserva-legal-arl/modulo-fiscal2018. Acesso em: 28 set. 2018

GUANZIROLI, Carlos; ROMEIRO, Ademar; BUAINAIN, Antônio M.; SABBATO, Alberto Di; BITTENCOURT, Gilson. Agricultura familiar e reforma agrária no século XXI. Rio de Janeiro: Garamond , 2001.

HAGUETTE, Teresa Maria Frota. Metodologias qualitativas na Sociologia. Petrópolis: Vozes, 1987.

INSTITUTO DE GEOGRAFIA E ESTATÍSTICA (IBGE). Censo agropecuário, florestal e aquícola - 2017. Rio de Janeiro: IBGE, 2017. Disponível em https://censos.ibge.gov.br/agro/2017/resultados-censo-agro-2017. html. Acesso em: 9 maio 2019. 
INSTITUTO NACIONAL DE COLONIZAÇÃO E REFORMA AGRÁRIA (INCRA). Módulos fiscais por estados da federação., Brasília-DF: INCRA, 2018. Disponível em: http://www.incra.goc.br/tabela-modulo-fiscal. Acesso em: 10 maio 2019

Instituto Estadual do Ambiente [INEA]. Plano de manejo da APA Macaé de Cima. [Módulo 1]. Rio de Janeiro: INEA/DIBAP, 2014. Disponível em: http://www.inea.rj.gov.br/cs/groups/public/ documents/document/ zwew/mdgz/ edisp/inea0083753.pdf. Acesso em: 10 dez. 2016.

LOPES, Mauro de Rezende. Política agrária - uma década de deterioração. Agroanalysis, Rio de Janeiro, v. 16, n. 4, p. 18-20, abr. 1996. Disponível em: http://bibliotecadigital.fgv.br/ojs/index.php/agroanalysis/ article/viewFile/48188/46098. Acesso em: 11 mar. 2018.

MARAFON, Gláucio José; RIBEIRO, Miguel Ângelo. Agricultura familiar, pluriatividade e turismo rural: reflexões a partir do território fluminense. Revista Rio de Janeiro, Rio de Janeiro, v. 3, n. 18-19, p. 111130, jan./dez. 2006.

MAYER, Jorge Miguel. Presença suíça e alemã na região serrana fluminense. In: PAOLINO, Claudio; BOTELHO, Marjorie (Org.). Agricultores do estado do Rio de Janeiro.. Rio de Janeiro: Instituto de Imagem e Cidadania, 2011. (Memória Fluminense - Pesquisa e Publicações). Disponível em: https://issuu.com/ sobradocultural/docs/www.imagemcidadania.blogspot.com. Acesso em: 11 mar. 2018.

MEDINA, Gabriel; NOVAES, Evandro. Percepção dos agricultores familiares sobre suas condições de vida. Interações, Campo Grande, MS, v. 14, n. 2, p. 385-97, jul./dez. 2014. Disponível em: http://www.interacoes. ucdb.br/article/view/116. Acesso em: 13 jul. 2018.

NOVA FRIBURGO (Cidade). Decreto Municipal n. 156, de 3 de janeiro de 1990. Cria a Reserva Ecológica de Macaé de Cima. Nova Friburgo, RJ, 1990. Disponível em: http://www.cea.xpg.com.br/apas_macae. htm. Acesso em: 10 dez. 2016.

PERES, Frederido; LUCCA, Sérgio Roberto de; PONTE, Luciana Muller da; RODRIGUES, Karla Meneses; ROZEMBERG, Brani. Percepção das condições de trabalho em uma tradicional comunidade agrícola em Boa Esperança, Nova Friburgo, Rio de Janeiro, Brasil. Caderno de Saúde Pública, Rio de Janeiro, v. 20, n. 4, p. 1059-68, jul./ago. 2004.

PETROBRAS. Petróleo Brasileiro S/A. Bacia de Campos - conheça as plataformas de produção. Petrobras, Rio de Janeiro, [s.d.]. Disponível em: http://www.petrobras.com.br/pt/nossas-atividades/principaisoperacoes/bacias/bacia-de-campos.htm. Acesso em: 28 set. 2018.

RANGEL, Ana Rita Moreira; OLIVEIRA, Vicente de Paulo Santos de; MOREIRA, Marcos Antonio Cruz. O programa Rio Rural no estado do Rio de Janeiro: a experiência na microbacia Canal Jurumirim, município de Macaé. Revista Monografias Ambientais - REMOA, Santa Maria, v. 15, n. 1, p. 302-22, jan./abr. 2016. Disponível em: https://periodicos.ufsm.br/remoa/article/viewFile/19948/pdf. Acesso em: 11 mar. 2018.

REGO, Virginia Villas Boas Sá. Mundos em confronto: o desenvolvimento do capitalismo e a educação numa comunidade camponesa. 1988. Dissertação (Mestrado em Educação) - Pontifícia Universidade Católica do Rio de Janeiro, Rio de Janeiro, RJ, 1988.

REGO, Virginia Villas Boas Sá. Paraísos Perdidos ou preservados: os múltiplos sentidos da cidadania em áreas de proteção ambiental. 2010. Tese (Doutorado em Meio Ambiente) -Universidade Estadual do Rio de Janeiro, Rio de Janeiro, RJ, 2010.

RIO DE JANEIRO (Estado). Decreto Estadual 29.213, de 14 de setembro de 2001. Cria Área de Proteção Ambiental Macaé de Cima. Diário Oficial do Estado do Rio de Janeiro, Rio de Janeiro, 17 de setembro de 2001. 
RIO DE JANEIRO (Estado). Programa de Desenvolvimento Rural Sustentável em Microbacias Hidrográficas. Rio de Janeiro, 2014. Disponível em: http://greenrio.com.br/arquivos/Programa_de_Desenvolvimento_ Rural_Sustentavel_em_Microbacias_Hidrograficas_-_Nelson_Teixeira.pdf. Acesso em: 18 mai. 2021.

ROCHA, Aurea Pinheiro. A escola está inserida na APA? - percepção socioambiental dentro da Área de Proteção Ambiental de Macaé de Cima. 2012. Dissertação (Mestrado em Ciência Ambiental) - Universidade Federal Fluminense, Niterói, RJ, 2012.

ROCHA, Aurea Pinheiro; DI MAIO, Angelica Carvalho; CAMPOS, Leonardo Gama. Percepção ambiental na Área de Proteção Ambiental de Macaé de Cima: perspectivas para o ecoturismo. Revista Brasileira de Ecoturismo, São Paulo, v. 4, n. 4, 2011. [Anais do VIII Congresso Nacional de Ecoturismo e do IV Encontro Interdisciplinar de Ecoturismo em Unidades de Conservação].

SCHIAVO, Sylvia França. Sendas da transição - descendentes de suíços em Nova Friburgo-RJ. Niterói: Eduff, 1997.

SILVA, José Graziano; GROSSI, Mario Del; CAPANHOLA, Clayton. O que há de realmente novo no rural brasileiro? Cadernos de Ciência \& Tecnologia, Brasília, v. 19, n. 1, p. 37-67, jan./abr. 2002. Disponível em: https://seer.sct.embrapa.br/index.php/c ct/article/view/8795. Acesso em: 11 mar. 2018.

TEIXEIRA, Vanessa Lopes. Novos contornos ocupacionais no meio rural fluminense: um estudo sobre a pluriatividade entre agricultores familiares. 2009. Tese (Doutorado em Ciências Econômicas) - Instituto de Economia, Universidade Estadual de Campinas, Campinas, SP, 2009.

VALLADARES, Licia. Os dez mandamentos da observação participante. Revista Brasileira de Ciências Sociais, São Paulo, v. 22, n. 63, p. 153-5, 2007. Disponível em: http://www.scielo.br/scielo.php?pid =S0102-69092007000100012\& script=sci_arttext\&tlng=es. Acesso em: 11 mar. 2018.

WHYTE, William Foote. Sociedade da esquina: a estrutura social de uma área urbana pobre e degradada. Rio de Janeiro: Jorge Zahar, 2005.

\section{Sobre as autoras:}

Cristiane Passos de Mattos: Doutorado em Psicossociologia de Comunidades e Ecologia Social pela Universidade Federal do Rio de Janeiro (UFRJ). Docente do Curso Superior de Tecnologia em Gestão de Turismo do Centro Federal de Educação Tecnológica Celso Suckow da Fonseca (CEFET-RJ). E-mail: crispassinhos@gmail.com, Orcid: http://orcid.org/0000-0001-5612-2566

Marta de Azevedo Irving: Pós-doutorado na Escola de Altos Estudos em Ciências Sociais (EHESS) de Paris e no Departamento de Ecologia e Gestão da Biodiversidade do Museu de História Natural de Paris. Doutorado em Ciências pela Universidade de São Paulo (USP). Mestrado pela Universidade de Southampton (UK). Formação interdisciplinar, com graduação em Biologia pela Universidade Federal do Rio de Janeiro (UFRJ), e Psicologia pela Universidade Estadual do Rio de Janeiro (UERJ). Lidera o Grupo de Pesquisa Governança, Ambiente, Políticas Públicas, Inclusão e Sustentabilidade (GAPIS-Lattes CNPq). Compõe o núcleo de coordenação do Curso de Especialização em Gestão da Biodiversidade da Escola Nacional de Botânica Tropical (Jardim Botânico, RJ). Professora titular da UFRJ. E-mail: mirving@mandic.com.br, Orcid: http://orcid.org/0000-0003-2677-818X

Lilia dos Santos Seabra: Pós-doutorado no Museu Nacional/Universidade Federal do Rio de Janeiro (UFRJ). Doutorado em Geografia pela UFRJ. Mestrado em Ciência Ambiental pela Universidade Federal Fluminense (UFF). Graduação em Geografia pela UFR e em História 
pela Universidade Federal do Estado do Rio de Janeiro (UNIRIO). Atualmente, é professora Associada da Universidade do Estado do Rio de Janeiro e coordenadora do Laboratório de Geografia da Baixada Fluminense (LabGeo Baixada Fluminense). E-mail: liliaseabra@oi.com.br, Orcid: http://orcid.org/0000-0002-3287-9369 
